\title{
Case-control study to evaluate risk factors for acute hepatitis B virus infection in Egypt
}

M. Talaat, ${ }^{1}$ E. Radwan, ${ }^{2}$ N. El-Sayed, ${ }^{2}$ T. Ismael, ${ }^{1}$ R. Hajjeh ${ }^{3}$ and F.J. Mahoney ${ }^{3}$

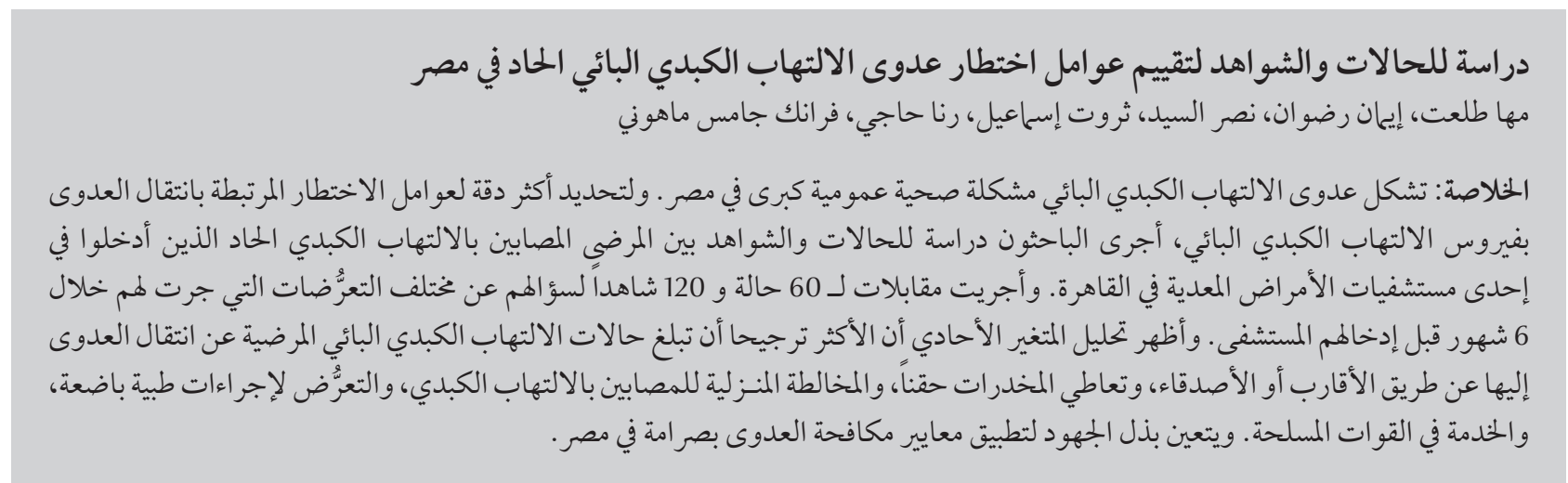

ABSTRACT Hepatitis B virus (HBV) infection is a significant health problem in Egypt. To better define risk factors associated with HBV transmission, we conducted a case-control study among patients admitted with acute hepatitis to an infectious disease hospital in Cairo. A total of 60 cases and 120 controls were interviewed about various exposures within 6 months prior to admission. Univariate analysis revealed HBV case-patients were more likely to report providing injections to relatives or friends, injecting drug use, exposure to a household contact with hepatitis, exposure to invasive medical procedures and being in the military. Efforts should be made to implement strict infection control standards in Egypt.

Étude cas-témoin visant à évaluer les facteurs de risque d'infection aiguë par le virus de l'hépatite B en Égypte

RÉSUMÉ L'infection par le virus de l'hépatite B (VHB) est un important problème sanitaire en Égypte. Afin de mieux définir les facteurs de risque associés à la transmission du virus de l'hépatite $B$, nous avons réalisé une étude castémoin parmi des patients admis pour une hépatite aiguë dans un hôpital pour maladies infectieuses du Caire. Au total, 60 patients atteints par la maladie et 120 témoins ont été interrogés sur les différents types d'exposition au cours des six mois précédant l'hospitalisation. L'analyse univariée a révélé que les sujets contaminés par le VHB avaient davantage tendance à déclarer avoir administré des injections à des parents ou à des amis, être consommateurs de drogues injectables, avoir été exposés à un contact avec une personne atteinte d'hépatite au domicile ou à des procédures médicales invasives et à servir dans l'armée. Des efforts devraient être faits pour mettre en œuvre des normes strictes de lutte contre les infections en Égypte. 


\section{Introduction}

Hepatitis B virus (HBV) infection is a serious global public health problem with an estimated 2 billion people infected worldwide and 350 million persons with chronic HBV infection. The World Health Organization estimates that 500000 to 1.2 million deaths occur each year due to HBV-related chronic liver disease, and that cirrhosis of the liver and primary hepatocellular carcinoma associated with HBV infection is the 10th leading cause of death worldwide $[1,2]$.

The epidemiology of HBV transmission is complex. Transmission occurs in all age groups associated with percutaneous and permucosal exposure to infectious body fluids from persons with acute or chronic HBV infection. The highest concentrations of HBV occur in blood and serous fluids, and infection most frequently occurs through direct inoculation of the virus through unsafe injections or reuse of contaminated medical equipment. Other common modes of transmission include sexual contact with infected persons and births from HBV-infected mothers $[3,4]$.

The epidemiology of $\mathrm{HBV}$ infection in Egypt has not been well characterized. Cross-sectional studies indicate that $\mathrm{HBV}$ is of intermediate endemicity, with $3 \%$ to $5 \%$ of the population having chronic HBV infection $[4,5]$. Hospital-based data indicate that HBV is a common cause of disease, accounting for approximately $30 \%$ of patients with acute viral hepatitis [6]. Most studies characterizing risk factors for HBV infection in Egypt are cross-sectional studies among patients with prevalent disease. These studies have implicated a variety of exposures associated with infection, including unsafe injections, unsafe medical care, community-acquired practices and others. For patients with acute HBV disease, there are no published studies to identify risk factors to help define intervention strategies.
During 2002-03, we conducted a casecontrol study to determine current preventable risk factors associated with transmission of acute HBV infection in Egypt, and to explore the epidemiological characteristics of patients with acute disease.

\section{Methods}

\section{Selection of cases and controls}

Case-patients and controls were recruited from Abbassia Infectious Disease Hospital, the largest infectious disease hospital in Cairo, Egypt. Cases enrolled in the study included patients evaluated in a sentinel surveillance system for acute viral hepatitis. Cases of acute hepatitis were defined as patients $>12$ months of age, with discrete onset of jaundice (or elevated serum aminotransferase levels, if performed), and no underlying medical conditions associated with acute or chronic liver disease. Cases of acute HBV infection were defined as cases of acute hepatitis with detection of IgM-class antibody to hepatitis B core antigen (anti-HBc) following serological testing. Controls were identified from the hospital log books of patients admitted to the same hospital with any diagnosis other than hepatitis and with no jaundice on the same day of confirmation of diagnosis of the HBV case patients. Cases were recruited consecutively and no patients refused to participate in the study. Two controls were selected for each case and were matched by age (to within 5 years) and sex.

The Institutional Review Board of the US Naval Medical Research Unit No. 3 (NAMRU-3) approved the study procedures. The attending physicians explained the study procedures and obtained informed consent/assent from all study subjects or their guardians.

\section{Data collection}

Sample size calculations used to estimate the appropriate size of the study population suggested 60 cases and 120 controls to achieve a confidence level of $95 \%$ and a power of $80 \%$. The risk of exposure to injections among cases was calculated as $28 \%$, whereas the risk of exposure to injections among controls was estimated as $10 \%$.

Cases and controls were interviewed by trained social workers using a standard questionnaire. Information was collected on demographic characteristics, history of vaccination and risk factors for exposure to HBV that occurred within 6 months prior to the onset of disease, including invasive health care procedures, blood transfusions, frequency and types of injections, injecting drug use, contact with infected persons and sexual practices. In addition, community-acquired risk factors were explored, such as sharing toothbrushes or razors and household contact with hepatitis patients. Information on other community exposures, such as circumcision, tattooing and acupuncture, was also collected.

\section{Laboratory tests}

Acute HBV infection was identified by the presence of hepatitis B surface antigen ( $\mathrm{HBsAg}$ ) in serum and the development of anti-HBc [7]. HBsAg antibodies to hepatitis $B$ surface antigen (anti-HBs) and anti-HBc (immunoglobulin $\operatorname{IgM}$ ) were detected by enzyme-linked immunoassay (ELISA) (Abbott Murex Biotech, UK).

\section{Data analysis}

Risk factors were grouped into 4 categories based on exposure patterns. The first group included exposures associated with health care, such as visiting an outpatient clinic, receiving a blood transfusion, receiving an injection, visiting a dentist and exposure to any invasive procedure during the last 6 months, including surgery, dialysis, insertion of 
intravenous (IV) cannula, wound and abscess treatment and stitches. The second group of exposures included personal practices that might be associated with infection, such as providing injections, being shaved at a community barber, having household contacts with hepatitis and using recreational drugs. The third group of risk factors included high-risk sexual practices, defined as having multiple sexual partners or engaging in homosexual activity. The final group of risk factors included military service or being imprisoned during the previous 6 months.

The data were entered into an inhouse computerized database. Univariate and multivariate analyses were conducted and logistic regression was performed to identify risk factors independently associated with the risk of acquiring disease. The model included variables significant on univariate analysis. For variables that might influence the occurrence of acute HBV, we calculated odds ratios (OR) and the $P$-value. $P<0.05$ was considered statistically significant.

\section{Results}

Among 2416 patients with acute hepatitis evaluated during the sentinel surveillance at the Abbassia Infectious Disease Hospital from 2002 to 2004, 515 (21.3\%) were diagnosed with acute $\mathrm{HBV}$ infection based on the case definition above. The mean age of patients with acute disease was 32 years with a range of $2-85$ years; $62 \%$ of patients were males. Among the 515 patients with acute $\mathrm{HBV}$ infection, 497 were born after integration of HBV vaccine into the Expanded Programme on Immunization (EPI) in Egypt. From these 515 patients, 60 were recruited from the 2002-03 time period to participate in the case-control study and were matched with 120 controls.

\section{Demographic characteristics}

Case-patients with acute HBV infection were matched with controls with respect to age (median 25 years for cases versus 27 years for controls) and sex. They were also similar with regard to job category, marital status, illiteracy and history of hepatitis $B$ vaccination (Table 1).

\section{Risk factors}

\section{Health care-related risk factors}

Of the various health care-related risk factors explored, the only one found to be associated with increased risk of disease was exposure to invasive medical procedures (insertion of IV line, surgery, wound or abscess treatment and suturing) [odds ratio $(\mathrm{OR})=2.2$ ] (Table 2). Health care exposures not associated with acute HBV infection included receiving blood transfusions, visiting a dentist, being hospitalized, receiving injections and visiting a physician clinic.

\section{Personal behaviour and household exposures}

Personal behaviour and household exposures significantly associated with infection included injecting drug use $(\mathrm{OR}=9.2)$, exposure to a household contact with hepatitis $(\mathrm{OR}=3.9)$ and providing injections to relatives or friends $(\mathrm{OR}=5.4)$ (Table 2). A number of personal behaviours were not associated with infection, such as being shaved by a public barber, receiving tattoos, having pierced ears and sharing toothbrushes. Cases were more likely to report high-risk sexual activity $(\mathrm{OR}=$ $2.5)$, incarceration $(\mathrm{OR}=3.9)$ and military service $(\mathrm{OR}=3.5)$ in the 6 months prior to admission when compared with the control group, although only the association with military service was statistically significant.

Table 1 Demographic characteristics of case-patients with acute hepatitis B virus (HBV) infection and controls attending Abbassia Infectious Disease Hospital, Egypt

\begin{tabular}{|c|c|c|c|c|}
\hline \multirow[t]{2}{*}{ Demographic characteristic } & \multicolumn{2}{|c|}{ HBV cases $(n=60)$} & \multicolumn{2}{|c|}{ Controls $(n=120)$} \\
\hline & No. & $\%$ & No. & $\%$ \\
\hline Median age (years) & \multicolumn{2}{|c|}{25.5} & \multicolumn{2}{|c|}{27.5} \\
\hline \multicolumn{5}{|l|}{ Sex } \\
\hline Male & 49 & 81.7 & 98 & 81.7 \\
\hline Female & 11 & 18.3 & 22 & 18.3 \\
\hline \multicolumn{5}{|l|}{ Marital status } \\
\hline Married & 27 & 45.0 & 70 & 58.3 \\
\hline Single & 33 & 55.0 & 50 & 41.7 \\
\hline \multicolumn{5}{|l|}{ Education } \\
\hline Illiterate & 24 & 40.0 & 35 & 29.9 \\
\hline Basic education & 36 & 60.0 & 82 & 70.1 \\
\hline \multicolumn{5}{|l|}{ Occupation } \\
\hline Housewife or not working & 10 & 16.9 & 23 & 19.2 \\
\hline Handicraft & 15 & 25.4 & 20 & 16.7 \\
\hline Government employee & 3 & 5.1 & 21 & 17.5 \\
\hline Manual labourer & 27 & 45.7 & 54 & 45.0 \\
\hline Health professional & 4 & 6.8 & 2 & 1.7 \\
\hline \multicolumn{5}{|l|}{ History of HBV vaccination } \\
\hline Vaccinated & 2 & 3.3 & 3 & 2.5 \\
\hline Not vaccinated & 58 & 96.7 & 117 & 97.5 \\
\hline
\end{tabular}

Data were not recorded in some categories. 


\begin{tabular}{|c|c|c|c|c|c|c|}
\hline \multirow[t]{2}{*}{ Risk factor } & \multicolumn{2}{|c|}{ HBV cases } & \multicolumn{2}{|c|}{ Controls } & \multirow[t]{2}{*}{ OR $(95 \% \mathrm{Cl})$} & \multirow[t]{2}{*}{$P$-value } \\
\hline & No. & $\%$ & No. & $\%$ & & \\
\hline \multicolumn{7}{|l|}{ Health care-related } \\
\hline Receiving blood transfusion & $5 / 58$ & 8.6 & 4/118 & 3.4 & $2.7(0.6-12.5)$ & 0.1 \\
\hline $\begin{array}{l}\text { Exposure to invasive medical } \\
\text { procedure }^{a}\end{array}$ & $16 / 60$ & 26.7 & $17 / 120$ & 14.2 & $2.2(0.9-5.1)$ & 0.04 \\
\hline Visiting a dentist & $12 / 59$ & 20.3 & $27 / 120$ & 22.5 & $2.7(1.1-6.9)$ & 0.3 \\
\hline Receiving injections & $40 / 60$ & 66.7 & $81 / 120$ & 67.5 & $0.9(0.5-2.0)$ & 0.9 \\
\hline Hospitalization & $6 / 60$ & 10.0 & $16 / 120$ & 13.3 & $0.7(0.2-2.1)$ & 0.7 \\
\hline Visiting a doctor & $22 / 59$ & 37.3 & $53 / 119$ & 44.5 & $0.7(0.3-1.5)$ & 0.4 \\
\hline \multicolumn{7}{|l|}{ Personal behaviour } \\
\hline Injecting drug use & $8 / 59$ & 13.6 & $2 / 119$ & 1.7 & $9.2(1.7-65.0)$ & 0.003 \\
\hline $\begin{array}{l}\text { Contact with hepatitis case in } \\
\text { household }\end{array}$ & $13 / 59$ & 22.0 & $8 / 120$ & 6.7 & $3.9(1.4-11.3)$ & 0.005 \\
\hline Providing injections & $8 / 42$ & 19.0 & 4/95 & 4.2 & $5.4(1.3-22.9)$ & 0.007 \\
\hline Shaving at barber (for males) & $36 / 47$ & 76.6 & $61 / 97$ & 62.9 & $1.9(0.8-6.4)$ & 0.1 \\
\hline \multicolumn{7}{|l|}{ Unsafe sexual practices } \\
\hline Multiple partners/homosexuality & $11 / 60$ & 18.3 & $10 / 120$ & 8.3 & $2.5(0.9-6.8)$ & 0.08 \\
\hline \multicolumn{7}{|l|}{ Other exposure } \\
\hline Being imprisoned & $5 / 44$ & 11.4 & $3 / 93$ & 3.2 & $3.9(0.8-21.6)$ & 0.07 \\
\hline Military service (for males) & $9 / 48$ & 18.8 & $6 / 97$ & 6.2 & $3.5(1.1-12.0)$ & 0.04 \\
\hline
\end{tabular}

${ }^{a}$ Includes surgery, insertion of intravenous cannula, wound or abscess treatment and stitches; injections were excluded. $O R=$ odds ratio; $C l=$ confidence interval.

\section{Multivariate analysis}

The multivariate model included variables significant on univariate analysis: military service, providing medical injections, injecting drug use, exposure to invasive procedures and contact with a household member with hepatitis. Three factors remained independently associated with increased risk of $\mathrm{HBV}$ infection: military service $(\mathrm{OR}=19.2$; 95\% CI: 2.7-135.6), providing injections $(\mathrm{OR}=8.7$; 95\% CI: $1.1-72.1)$ and exposure to invasive medical procedures $(\mathrm{OR}=5.6$; 95\% CI: 1.1-27.2).

\section{Discussion}

Prevention of bloodborne pathogen transmission is a high priority for the Ministry of Health and Population (MOHP) in Egypt. While the modes of transmission of human immunodeficiency virus (HIV), hepatitis C virus (HCV) and HBV infection are similar, the contribution of different exposures to overall disease burden varies significantly in different countries and regions. Identifying specific risk factors for bloodborne pathogen transmission

\begin{tabular}{lc}
\hline \multicolumn{2}{l}{ Table 3 Multivariate analysis for risk factors of acute hepatitis B virus (HBV) } \\
infection, Abbassia Infectious Disease Hospital, Egypt \\
\hline Risk factor & OR (95\% CI) \\
Military service & $19.2(2.7-135.6)$ \\
Providing injections & $8.7(1.1-72.1)$ \\
Exposure to invasive medical procedure & $5.6(1.1-27.2)$ \\
Injecting drug use & $6.9(0.5-83.4)$ \\
Contact with household hepatitis case & $3.8(0.9-14.6)$ \\
Unsafe sexual practices & $1.2(0.2-6.1)$ \\
\hline
\end{tabular}

$O R=$ odds ratio; $C I=$ confidence interval. of public health importance is a challenging but important step in the development of prevention strategies. Epidemiological studies suggest that the prevalence of HIV infection is low in Egypt and there are few studies characterizing behaviours associated with transmission. HCV infection on the other hand is highly endemic in Egypt where $10 \%-15 \%$ of the population has evidence of chronic HCV infection [8]. Chronic liver disease associated with $\mathrm{HCV}$ infection is one of the major causes of death in Egypt. Numerous studies have identified diverse risk factors associated with HCV transmission $[9,10]$; however, none of these has evaluated patients with acute disease. It is challenging to identify patients with acute HCV infection due to the lack of a diagnostic marker (IgM antibody) that can differentiate patients with acute versus chronic infection. Similar to HIV and HCV, there are few studies evaluating the risks associated with HBV transmission in Egypt. 
HBV exists in high titres in blood and infectious body fluids among persons with chronic infection and is more easily transmitted than other bloodborne pathogens [11]. With the introduction of the hepatitis $B$ vaccine in 1992, it is unlikely that early childhood transmission continues to contribute to overall disease burden. Indeed, the sentinel surveillance system identified few cases who were born since the introduction of vaccines and found that most transmission occurred among young adult males. This age coincides with the onset of high-risk behaviours, such as unsafe sexual practices and injecting drug use. Thus, we hypothesized that these high-risk behaviours are key risk factors for infection. The findings of our study suggested that military service, exposure to invasive medical procedures, injecting drug use, contact with an infected household member and providing injections to others contributed to the transmission of acute HBV infection in Egypt. Few of these exposures were identified in a large proportion of patients with acute HBV infection, thus making the identification of risk groups for prevention difficult. The lack of a significant association with highrisk sexual behaviours was somewhat surprising and may reflect difficulties in eliciting information on these exposures within the cultural context of Egypt.

The finding that exposure to unsafe invasive medical procedures contributes to HBV transmission is consistent with other studies, indicating deficiencies in standard infection control precautions in the local health care setting $[8-10]$. The MOHP started to implement a national infection control programme in 2001 and has adopted a comprehensive strategy to implement practices to prevent transmission of bloodborne pathogens in health care settings [12]. However, performance of some invasive procedures through the informal sector remains a risk, and awareness campaigns directed towards the public need to be launched to raise public demand for safety.

The lack of association between HBV and receipt of injections, with the exception of injecting drug use, was surprising, based on data from other studies suggesting that reuse of needles is relatively common in Egypt [13]. It is estimated that unsafe injections may cause 8-16 million HBV infections each year worldwide, most of which occur in developing countries [14]. The similar proportions who received injections among cases and controls might be the reason for this lack of association. Community-based studies reveal a much lower frequency of receiving injections in the general population when compared to our control population, thus it is possible that the control population (hospitalized patients) may have introduced a bias against demonstrating an association of unsafe injections and HBV infection.

The association of serving in the military with HBV infection has not been reported in other studies. Military recruits in Egypt are housed in compounds where sharing of personal hygiene materials, such as razors or toothbrushes, is relatively common. Presumably such unapparent exposures would promote $\mathrm{HBV}$ transmission that has been observed among household contacts of persons with acute or chronic HBV infection.

Ourfindings also revealed that those imprisoned within the last 6 months had higher odds of being infected by HBV than controls, consistent with studies in other countries [15,16], although it was not statistically significance on univariate or multivariate analysis. For example, Macalino et al. reported that the prevalence of $\mathrm{HBV}$ infection among prisoners was $20.2 \%$ and was associated with injecting drug use $(\mathrm{OR}=10)$. Their study revealed that high-risk practices, such as injecting drug use, homosexuality or unsafe medical procedures, might be risk factors associated with transmission. The restrictive nature of the prison environment and the probable reuse of syringes heighten the hazards associated with high-risk activities [16]. General disease prevention efforts must include prevention within highrisk facilities, such as prisons, military facilities and others.

While it is likely that risk factors for HIV, HCV and HBV infection may vary, particularly in relation to attributable risk, it is anticipated that the identification of risk factors and development of prevention strategies based on the findings of this study and others can form the basis for developing a comprehensive prevention strategy to prevent bloodborne pathogen transmission in Egypt. The strategy should include a programme targeting HBV prevention efforts, including vaccination for highrisk groups and raising public awareness and demands for safety and promotion of infection control standards in the health care setting.

\section{Acknowledgements}

The authors would like to thank with great appreciation the support provided by Dr Yehia Sultan, the Director of Abbassia Infectious Disease Hospital, and the hepatitis coordinators who participated in enrolling the patients.

This work was supported by USAID, Work Unit no. 80000.000.000. E0022. The views expressed in this article are those of the authors and do not necessarily reflect the official policy or position of the Department of the Navy, Department of Defense, the US Government or the Egyptian Ministry of Health and Population. The study protocol was approved by the US Naval Medical Research Unit No. 3 Institutional Review Board (Protocol \# NAMRU3.2003.003) and work was conducted in compliance with all US Federal regulations governing the protection of human subjects. 
This article fits the description stipulated by the new US Copyright Act of a "United States Government work." The authors are employees of the US Government and this work was prepared as part of their official duties. Title 17 USC 105 provides that "Copyright protection under this title is not available for any work of the United States Government work as a work prepared by a military service member or employee of the United States Government as part of that person's official duties."

\section{References}

1. Hepatitis B. Geneva, World Health Organization, 2008 (WHO Fact sheet, No. 204) (http://www.who.int/mediacentre/ factsheets/fs204/en/index.html, accessed 18 May 2009).

2. Lavanchy DJ. Hepatitis B virus epidemiology, disease burden, treatment, and current and emerging prevention and control measures. Viral hepatitis, 2004, 11:97-107.

3. Mahoney FJ. Update on diagnosis, management, and prevention of hepatitis B virus infection. Clinical microbiology reviews, 1999:351-66.

4. Qirbi N, Hall AJ. Epidemiology of hepatitis B virus infection in the Middle East. Eastern Mediterranean health journal, 2001, 7:1034-45.

5. Kamal M, Aoun S. Natural history of hepatitis C: factors contributing to the evolution and outcome of infection. Cairo, Egypt, Ministry of Health and Population, 1999.

6. Azab MA et al. Epidemiology of acute viral hepatitis in Egypt, 2001-2003. Abstract in the Proceedings of the International Conference on Emerging Infectious Diseases (ICEID). Atlanta, Georgia, 29 February 2004 to 3 March 2004.

7. Chau K et al. Serodiagnosis of recent hepatitis B virus infection by IgM class anti-HBc. Hepatology, 1983, 3:142-9.

8. Frank $\mathrm{C}$ et al. The role of parenteral antischistosomal therapy in the spread of hepatitis C virus in Egypt. Lancet, 2000, 11:887-91.
9. Habib $M$ et al. Hepatitis $C$ virus infection in a community in the Nile Delta: risk factors for seropositivity. Hepatology, 2001, 33:248-53.

10. Medhat $\mathrm{A}$ et al. Hepatitis $\mathrm{C}$ in a community in Upper Egypt: risk factors for infection. American journal of tropical medicine and hygiene, 2002, 66:633-8.

11. Margolis HS et al. Viral infections of humans: epidemiology and control, 4th ed. New York, Plenum, 1997.

12. Talaat $\mathrm{M}$ et al. Evolution of infection control in Egypt: achievements and challenges. American journal of infection control, 2006, 34(4):193-200.

13. Talaat $M$ et al. Overview of injection practices in two governorates in Egypt. Tropical medicine and international health, 2003, 8:234-41.

14. Kane A et al. Transmission of hepatitis $B$, hepatitis $C$ and human immunodeficiency viruses through unsafe injections in the developing world: model-based regional estimates. Bulletin of the World Health Organization, 1999, 77:801-7.

15. Khan AJ et al. Ongoing transmission of hepatitis B virus infection among inmates at a state correctional facility. American journal of public health, 2005, 95:1793-9.

16. Macalino GE et al. Prevalence and incidence of HIV, hepatitis $B$ virus, and hepatitis $C$ virus infections among males in Rhode Island prisons. American journal of public health, 2004, 94:1218-23.

\section{Note from the Editor}

We wish to draw the kind attention of our potential authors to the importance of applying the editorial requirements of EMHJ when preparing their manuscripts for submission for publication. These provisions can be seen in the Guidelines for Authors, which are available online at http://www.emro.who.int/emhj.htm, and are published at the end of the first issue of each volume. We regret that we are unable to consider papers that do not conform to the Guidelines. 